\title{
Lifetime risk of diabetes in metropolitan cities in India
}

\author{
Shammi Luhar ${ }^{1,2}$ (D) $\cdot$ Dimple Kondal $^{3}$ (I) $\cdot$ Rebecca Jones $^{4} \cdot$ Ranjit M. Anjana $^{5}$ (D) $\cdot$ Shivani A. Patel $^{6}$ (D) $\cdot$ Sanjay Kinra $^{7}$ (D) \\ Lynda Clarke $^{2}$ - Mohammed K. Ali ${ }^{6}$ (D) Dorairaj Prabhakaran $^{3,8}$ (D) $\cdot$ M. Masood Kadir ${ }^{9}$ (D) Nikhil Tandon ${ }^{10}$ (D) \\ Viswanathan Mohan $^{5}$ (D) K. M. Venkat Narayan ${ }^{6}$ (D)
}

Received: 29 July 2020 / Accepted: 5 October 2020 / Published online: 23 November 2020

(C) The Author(s) 2020

\begin{abstract}
Aims/hypothesis We aimed to estimate the lifetime risk of diabetes and diabetes-free life expectancy in metropolitan cities in India among the population aged 20 years or more, and their variation by sex, age and BMI.

Methods A Markov simulation model was adopted to estimate age-, sex- and BMI-specific lifetime risk of developing diabetes and diabetes-free life expectancy. The main data inputs used were as follows: age-, sex- and BMI-specific incidence rates of diabetes in urban India taken from the Centre for Cardiometabolic Risk Reduction in South Asia (2010-2018); age-, sex- and urban-specific rates of mortality from period lifetables reported by the Government of India (2014); and prevalence of diabetes from the Indian Council for Medical Research INdia DIABetes study (2008-2015).

Results Lifetime risk (95\% CI) of diabetes in 20-year-old men and women was $55.5(51.6,59.7) \%$ and 64.6 (60.0, 69.5)\%, respectively. Women generally had a higher lifetime risk across the lifespan. Remaining lifetime risk (95\% CI) declined with age to $37.7(30.1,46.7) \%$ at age 60 years among women and $27.5(23.1,32.4) \%$ in men. Lifetime risk (95\% CI) was highest among obese Indians: $86.0(76.6,91.5) \%$ among 20 -year-old women and $86.9(75.4,93.8) \%$ among men. We identified considerably higher diabetes-free life expectancy at lower levels of BMI.

Conclusions/interpretation Lifetime risk of diabetes in metropolitan cities in India is alarming across the spectrum of weight and rises dramatically with higher BMI. Prevention of diabetes among metropolitan Indians of all ages is an urgent national priority, particularly given the rapid increase in urban obesogenic environments across the country.
\end{abstract}

Keywords Body mass index $\cdot$ Diabetes $\cdot$ Diabetes-free life expectancy $\cdot$ India $\cdot$ Lifetime risk $\cdot$ Metropolitan cities $\cdot$ Urban

\section{Abbreviations \\ CARRS}

CBG

FPG

HIC
cArdiometabolic Risk Reduction

in South Asia study

Capillary blood glucose

Fasting venous plasma glucose

High-income country
Shammi Luhar

s1989@medschl.cam.ac.uk

1 Department of Public Health and Primary Care, University of Cambridge, Cambridge, UK

2 Department of Population Health, London School of Hygiene and Tropical Medicine, London, UK

3 Centre for Chronic Disease Control (CCDC), New Delhi, India

4 Nutrition and Health Sciences, Laney Graduate School, Emory University, Atlanta, GA, USA

5 Madras Diabetes Research Foundation, Chennai, India
ICMR-INDIAB Indian Council of Medical

Research-INdia DIABetes

LMIC Low- to middle-income country

SAGE Study on global AGEing and adult health

SRS Sample Registration System
6 Hubert Department of Global Health, Emory University, Atlanta, GA, USA

7 Department of Non-Communicable Disease Epidemiology, London School of Hygiene and Tropical Medicine, London, UK

8 Public Health Foundation of India, Gurgaon, India

9 Department of Community Health Sciences, Aga Khan University, Karachi, Pakistan

10 Department of Endocrinology and Metabolism, All India Institute of Medical Sciences, New Delhi, India 


\section{Research in context}

\section{What is already known about this subject?}

- South Asians have a high propensity to develop diabetes at lower weight levels and younger ages than white Europeans

- India is a rapidly urbanising country, contributing to its status as an epicentre of the global diabetes epidemic

What is the key question?

- What is the probability that a metropolitan Indian adult, at any age or BMI, will develop diabetes during their lifetime and what is his/her diabetes-free life expectancy?

What are the new findings?

- Over half of the men in metropolitan cities aged 20 years without diabetes will develop diabetes in their lifetime. Among women, $64.6 \%$ will develop diabetes

- At 20 years of age, lifetime risk of developing diabetes increases to $86.0 \%$ among obese women and $86.9 \%$ among obese men

- Whereas 20-year-old underweight/normal-weight individuals can expect to spend $79.6-84.7 \%$ of their remaining lifespan free from diabetes, this reduces to $46-52 \%$ among obese counterparts

\section{How might this impact on clinical practice in the foreseeable future?}

- Given the alarmingly high probability of developing diabetes at all levels of BMI in India's metropolitan cities and the rapid development of urban centres across the country, diabetes prevention is an increasingly important public health priority

\section{Introduction}

Diabetes is a major global public health problem currently affecting 463 million individuals and projected to affect 700 million by 2045 [1]. Estimates of prevalence suggest that the diabetes burden is increasing at a faster pace in low- to middleincome countries (LMICs) than in high-income countries (HICs). In India, 77 million adults currently have diabetes and this number is expected to almost double to 134 million by 2045 [1]. Whereas prevalence estimates are useful for expressing the overall burden of diabetes at a particular point in time, they do not inform future risk of developing this disease at the individual level. Lifetime risk provides an estimate of the cumulative probability of eventually developing diabetes over the course of life. It is a valuable estimate for effectively communicating diabetes risk to individuals, even at young ages, and is also a powerful tool with which to galvanise public health and policy responses. The few studies estimating the lifetime risk of developing diabetes are focused on HICs [2-4]. The population of India, while at the epicentre of the global diabetes epidemic, has a lower BMI distribution and lower overall life expectancy; Indian people also show a comparatively higher propensity to develop diabetes, both at younger ages and lower BMI levels [5], suggesting a substantially different epidemiology.

Studies from HICs such as the USA [2, 6], Australia [3] and the Netherlands [4] have found high lifetime risks of developing diabetes. For example, lifetime risk was $31.3 \%$ among 45-year-old individuals in the USA and 38.0\% among those aged 25 years in the Netherlands. The lifetime risk among severely obese people in the USA was reported to be as high as ten times that of underweight individuals [2]. The combination of a high BMI distribution, high incidence of diabetes and high life expectancy drive a high overall lifetime risk in HICs. It is not clear, however, how the lifetime risk of developing diabetes may differ in LMICs wherein individuals may have a comparatively lower BMI and life expectancy.

In this study, we estimated the lifetime risk of developing diabetes in India's metropolitan cities where an already large number of adults have diabetes and where there are rapid increases in population-level weight status and life expectancy [7]. Drawing on recent diabetes incidence data and on multiple Indian databases, we constructed a Markov model to estimate lifetime risk of diabetes in Indian metropolitan cities and also stratified by age, sex and BMI. We define metropolitan cities as per the Indian Census Commission's definition: cities with over four million inhabitants (including Delhi, Mumbai, Kolkata, Chennai, Hyderabad, Bangalore, Ahmedabad, Pune, Surat and Nashik [8]; making up just over 5\% of the population around the time of the last census [9]).

\section{Methods}

Lifetime risk estimation required, as data inputs, age-, sexand BMI-specific estimates of diabetes incidence and age-, 
sex- and BMI-specific rates of mortality by diabetes status. Differential risks of dying depending on diabetes and weight status, prevalence of diabetes and the prevalence of different BMI classes were used to modify population-level rates, making them specific to particular subgroups (i.e. BMI groups and individuals with and without diabetes).

This study was approved by the LSHTM Observational/ Interventions Research Ethics Committee (ref. 17568).

Incidence of diabetes Incidence of diabetes was calculated using data from the India cArdiometabolic Risk Reduction in South Asia study (CARRS) cohort [10, 11], a metropolitan based cohort of 9812 participants with high retention and multiple points of follow-up, representative of Delhi and Chennai. CARRS was established in 2010-2011 and is under ongoing follow-up. Fasting venous plasma glucose (FPG) and $\mathrm{HbA}_{1 \mathrm{c}}$ data were collected at baseline in 2010-2011 as well as at the second and fourth follow-up assessments in 2013 and 2016, respectively. Age-specific population estimates of incidence were restricted to participants without diabetes at baseline and the annualised incidence rate was calculated at the second (2013) and fourth (2016) follow-up assessments. Incident diabetes was defined as occurring in an individual reporting no diabetes at baseline and baseline biochemical variables in the non-diabetes range (FPG $<7 \mathrm{mmol} / \mathrm{l}$ and $\mathrm{HbA}_{1 \mathrm{c}}<48 \mathrm{mmol} / \mathrm{mol}$ [6.5\%]) who subsequently recorded an $\mathrm{FPG} \geq 7 \mathrm{mmol} / \mathrm{l}$ or $\mathrm{HbA}_{1 \mathrm{c}} \geq 48 \mathrm{mmol} / \mathrm{mol}(6.5 \%)$ or reported diabetes treatment during follow-up. Incidence for the following age groups was available: $20-24$ years; $25-34$ years; 35-44 years; $45-54$ years; $55-64$ years; and $\geq 65$ years. Using the RR of diabetes among different BMI groups, we modified the population rates to estimate incidence separately for the underweight/normal weight (BMI $<25.0 \mathrm{~kg} / \mathrm{m}^{2}$ ), overweight (BMI $25.0-29.9 \mathrm{~kg} / \mathrm{m}^{2}$ ) and obese population (BMI $\geq 30.0 \mathrm{~kg} /$ $\mathrm{m}^{2}$ ) [12]. We report the incidence rates, in addition to the number of incident cases, from the CARRS study in the electronic supplementary material (ESM) Tables 1-5. Incidence rates by single years were subsequently extracted after fitting a cubic smoothing spline.

Population mortality rates Mortality rates by 5 year intervals were extracted from the latest Sample Registration System (SRS), which contains abridged lifetables for 2013-2017 by sex and urban residence [13]. The SRS provides conditional probabilities of death (lifetable notation $={ }_{n} q_{x}$ ), which we used to obtain age-specific mortality rates using an inversion of Chiang's formula [14]. We obtained mortality rates by single years by fitting an age at death distribution to the 5 year mortality rates. Specifically, we used the GompertzMakeham law of mortality, which is made up of two separate components: an age-dependent part that states that the rate of mortality increases exponentially with age, representing the underlying mortality age pattern; and a component independent of age used to account for external causes of death, which may be especially high in early adulthood [14]. The mortality rates derived from the SRS lifetables are included in ESM Table 6 and the fit of the population mortality rates is shown in the ESM Figs 1-2. From this, we extracted predicted mortality rates by single years [15].

Differential mortality rates by diabetes and BMI status A meta-analysis of 35 published articles between 1990 and 2010 (220,689 individuals in HICs, mean follow-up 10.7 years) informed differential mortality rates in individuals with vs without diabetes. The study found $85 \%$ and $100 \%$ higher risk of all-cause mortality among men and women, respectively, for those with vs without type 2 diabetes [16]. We accounted for differential mortality among populations with different BMI status by applying RRs of dying by BMI group from a study that examined the association of BMI with mortality risk in urban Mumbai between 1991 and 2003 [17]. The study, comprising 148,173 individuals, reported $11 \%$ lower risk and $22 \%$ higher risk, of dying among overweight and obese men aged 35-59 years, respectively, compared with normal-weight men. Furthermore, they identified a $67 \%$ and $102 \%$ higher risk of death in underweight women and men, respectively, relative to normal-weight counterparts. Slightly attenuated RRs were found in individuals aged 60 years or more. For details of how differential mortality rates were calculated for the analysis, see ESM Methods.

Age-specific prevalence of diabetes Diabetes prevalence data were used to compartmentalise population rates of mortality into a set of rates specific to the population with and without diabetes. Age-specific diabetes prevalence was obtained from the Indian Council of Medical Research-INdia DIABetes (ICMR-INDIAB) study [18]. The ICMR-INDIAB study is the largest representative study with fasting glucose measures in India and includes data collected between 2008 and 2015 from 57,117 Indians from 14 states and one Union Territory. The ICMR-INDIAB study used $8 \mathrm{~h}$ fasting capillary blood glucose (CBG) measured by trained field workers to identify adults with previously undiagnosed diabetes. CBG is seen as a reasonable alternative to venous blood glucose in developing countries and has reasonable sensitivity (83.3-90.9\%, depending on the diagnostic criteria) in India [19]. Using an $82.5 \mathrm{~g}$ oral glucose load (equivalent to $75 \mathrm{~g}$ of anhydrous glucose), $2 \mathrm{~h}$ post-load CBG was measured in individuals who did not self-report diabetes. Among those with selfreported diabetes, only fasting glucose was measured. Individuals with an $8 \mathrm{~h} \mathrm{CBG} \geq 7 \mathrm{mmol} / 1,2 \mathrm{~h} \mathrm{CBG}$ $\geq 12.2 \mathrm{mmol} / \mathrm{l}$, or both, were categorised as having diabetes. Age was categorised into groups of 5 years.

Age-specific prevalence of BMI categories We used the proportion of the urban population in broad BMI categories 
to estimate weighted averages of lifetime risk for the whole population. The age- and sex-specific prevalences of 'underweight/normal weight' (BMI $<25.0 \mathrm{~kg} / \mathrm{m}^{2}$ ), 'overweight' (BMI $25.0-29.9 \mathrm{~kg} / \mathrm{m}^{2}$ ) and 'obesity' (BMI $\geq 30.0 \mathrm{~kg} / \mathrm{m}^{2}$ ) groups across the whole age range in urban Indians were obtained from a study that forecasted weight category prevalence in India using survey data [20]. The study obtained BMI group prevalence from the 2015-2016 National Family and Health Survey, which collected nationally representative health and demographic data on approximately 625,000 adult women aged $15-49$ years and 93,000 adult men aged 15-54 years [21]. The Study on global AGEing and adult health (SAGE) wave 0 (2002-2004) and wave 1 (2007-2010) were used to obtain estimates of agespecific proportions of the urban population aged 50 years or more in broad BMI categories. SAGE is a nationally representative health and demographic study containing information on 2559 adults in wave 0 and approximately 3000 men and 3000 women in wave 1 [22].

The model We adopted a multistate Markov model to estimate the lifetime risk of diabetes [23]. A detailed and formal description of the methodology we adopted is described in a similar study [2]. The multistate model compartmentalises a population into three separate age-, sex- and BMI-specific groups: no diabetes; diabetes; and dead. The single-year incidence and mortality rates were inputted into a matrix of rates of which the exponential was subsequently taken to obtain a matrix of transition probabilities between the states based on starting age and state. This was performed separately by BMI category. These single-year transition probabilities, derived from the variables, simulated movements between the three mutually exclusive states (ESM Fig. 3) and the resultant transition matrix was used to generate measures of both lifetime risk of developing diabetes and diabetes-free life expectancy by single years. We were able to calculate total lifetime risk of developing diabetes as a weighted average of separate lifetime risk estimates for different BMI groups.

We performed multiple sensitivity analyses. First, we performed multiple simulations whereby we simultaneously selected random variables estimates from the distributions that informed their uncertainty. In total, 5000 simulations were carried out and the median lifetime risk estimate was reported as the final point estimate; the range of values at any age informed the uncertainty interval. Second, we supplemented our main lifetime risk estimates by BMI using South Asianspecific BMI cut-offs (BMI $<23.0 \mathrm{~kg} / \mathrm{m}^{2}$ for the underweight/ normal-weight group, $\mathrm{BMI} \geq 23.0 \mathrm{~kg} / \mathrm{m}^{2}$ to $<27.5 \mathrm{~kg} / \mathrm{m}^{2}$ for the overweight group and BMI $\geq 27.5 \mathrm{~kg} / \mathrm{m}^{2}$ for the obese group [24]). The higher positive relationship between body fat and BMI observed in South Asians when compared with white Europeans may make use of conventional BMI cut-offs inappropriate and lead to a relatively high disease risk at comparatively lower body weight [24]. Third, we tested the sensitivity of our model to the initial prevalence of diabetes (to modify diabetes and non-diabetes-specific mortality) using age-specific diabetes prevalence reported for the two Indian cities in the CARRS study, which used FPG rather than CBG used in the ICMR-INDIAB study, to determine diabetes status [25]. We also estimated the lifetime risk of developing diabetes using incidence rates that omitted $\mathrm{HbA}_{1 \mathrm{c}}$ in diagnosing diabetes. As individuals with incident diabetes can have normal FPG while having $\mathrm{HbA}_{1 \mathrm{c}} \geq 48 \mathrm{mmol} / \mathrm{mol}(6.5 \%)$, this may have led us to overestimate the main lifetime risk estimates as they may represent a group with higher glucose tolerance than those satisfying both FPG and $\mathrm{HbA}_{1 \mathrm{c}}$-related diagnostic criteria [26]. In addition to BMI, we also examined the lifetime risk of diabetes by categories of waist circumference. Finally, we examined the effect on the total population lifetime risk of a change in the proportion of urban Indians classified as overweight or obese. Age-specific forecasts of the prevalence of excessive weight and obesity in urban India were extracted from a recent study [20]. All analyses were performed using the R (version 3.6.2) statistical software package (available for download at https:// cran.r-project.org/bin/windows/base/old/3.6.2/).

\section{Results}

Main findings Overall, the lifetime risk (95\% CI) of developing diabetes among Indian metropolitans at age 20 years was 64.6 (95\% CI 60, 69.5)\% among women and 55.5 (51.6, $59.7) \%$ among men. At ages 40 and 60 years, the remaining lifetime risk $(95 \% \mathrm{CI})$ among women was $59.2(52.4,64.9) \%$ and $37.7(30.1,46.7) \%$, respectively, and among men aged 40 and 60 years was $47.3(42.4,52.3) \%$ and $27.5(23.1,32.4) \%$, respectively (Table 1 ).

As expected, we found a higher age-specific lifetime risk of developing diabetes in higher BMI groups compared with lower ones. At age 20 years, the lifetime risk $(95 \% \mathrm{CI})$ of developing diabetes among underweight/normal-weight men was $41.2(36.7,45.7) \%$ compared with $71.3(64.6,77.6) \%$ among overweight men and $86.9(75.4,93.8) \%$ among obese men. Similarly, at age 20 years, the lifetime risk (95\% CI) of developing diabetes among underweight/normal-weight women was $51.6(46.0,58.4) \%$ compared with 71.0 (61.0, $80.6) \%$ and $86.0(76.6,91.5) \%$ among overweight and obese women, respectively.

Across BMI groups, the largest difference in lifetime risk of developing diabetes was between underweight/normal weight and overweight individuals. To illustrate, among urban men aged 20 years, the lifetime risk was higher by approximately 30 percentage points in the overweight group (71.3\%) compared with the underweight/normal weight group $(41.2 \%)$, whereas the lifetime risk was around 15 percentage points higher in obese men aged 20 years $(86.9 \%)$ when compared with overweight counterparts. 
Table 1 Lifetime risk of developing diabetes by global BMI cut points in Indian metropolitan cities

\begin{tabular}{|c|c|c|}
\hline \multirow[t]{2}{*}{ BMI group } & \multicolumn{2}{|l|}{ Lifetime risk } \\
\hline & Men & Women \\
\hline \multicolumn{3}{|c|}{ Underweight/normal weight (BMI $<25 \mathrm{~kg} / \mathrm{m}^{2}$ ) } \\
\hline Age 20 years & $41.2(36.7,45.7)$ & $51.6(46,58.4)$ \\
\hline Age 40 years & $34.5(30.7,38.8)$ & $47.1(40.5,54.6)$ \\
\hline Age 60 years & $21.5(16.7,27.5)$ & $30.7(23.2,40.1)$ \\
\hline \multicolumn{3}{|c|}{ Overweight (BMI $\geq 25 \mathrm{~kg} / \mathrm{m}^{2}$ to $<30 \mathrm{~kg} / \mathrm{m}^{2}$ ) } \\
\hline Age 20 years & $71.3(64.6,77.6)$ & $71.0(61.0,80.6)$ \\
\hline Age 40 years & $63.8(54.0,72.1)$ & $64.9(54.1,77.8)$ \\
\hline Age 60 years & $44.9(32.2,56.1)$ & $45.9(30.8,65.6)$ \\
\hline \multicolumn{3}{|c|}{ Obese $\left(\mathrm{BMI} \geq 30 \mathrm{~kg} / \mathrm{m}^{2}\right)$} \\
\hline Age 20 years & $86.9(75.4,93.8)$ & $86.0(76.6,91.5)$ \\
\hline Age 40 years & $77.2(56.7,87.8)$ & $79.1(65.6,88.8)$ \\
\hline Age 60 years & $55.9(34.1,74.6)$ & $58.5(32.9,78.6)$ \\
\hline \multicolumn{3}{|l|}{ Total population } \\
\hline Age 20 years & $55.5(51.6,59.7)$ & $64.6(60.0,69.5)$ \\
\hline Age 40 years & $47.3(42.4,52.3)$ & $59.2(52.4,64.9)$ \\
\hline Age 60 years & $27.5(23.1,32.4)$ & $37.7(30.1,46.7)$ \\
\hline
\end{tabular}

Lifetime risk is presented as $\%(95 \% \mathrm{CI})$

Women at age 20 years can expect to live 38.9 of their remaining 54.4 years spent free of diabetes $(71.6 \%$ of their remaining life) (Table 2). Similarly, men aged 20 years can expect to live 39.9 years of their remaining 52.6 years free of diabetes $(75.9 \%)$. The remainder of life spent with diabetes varied considerably between BMI groups. Among underweight/normal weight women aged 20 years, on average, 43.4 years of an expected 54.5 remaining years $(79.6 \%)$ were estimated to be diabetes-free, compared with 27.1 years of the remaining 52.4 years of life of obese women aged 20 years $(51.8 \%)$.

Sensitivity analysis findings As expected, the overall lifetime risk of developing diabetes was attenuated when using South Asian-specific BMI cut-offs (Table 3). To illustrate, at age 20 years, the lifetime risk $(95 \% \mathrm{CI})$ of developing diabetes was 37.4 (33.1, 44.3)\% among underweight/normal-weight men, 63.6 (55.6, 71.9)\% among overweight men and 83.3 (73, 91.1)\% among obese men. For women aged 20 years, the lifetime risk $(95 \%$ CI) was $46.8(41.4,53.0) \%$ among underweight/ normal-weight women, $67.6(56.9,75.2) \%$ among overweight women and $80.3(69.5,88.3) \%$ among obese women. We also assessed the effect of using age-specific prevalence of diabetes from CARRS, rather than the ICMR-INDIAB prevalence. The effect of this on the lifetime risk estimates was negligible (a change of $0-1$ percentage points compared with initial estimates).

When using incidence rates that excluded $\mathrm{HbA}_{1 \mathrm{c}}$ in the determination of incident diabetes, we identified slightly different, although not notable, lifetime risk estimates (ESM

Table 2 Percentage of remaining life spent with diabetes in Indian metropolitan cities by global BMI cut points at ages 20,40 and 60

\begin{tabular}{|c|c|c|c|c|c|c|}
\hline \multirow[t]{2}{*}{ BMI group } & \multicolumn{3}{|l|}{ Men } & \multicolumn{3}{|l|}{ Women } \\
\hline & $\begin{array}{l}\text { Life expectancy } \\
\text { (years) }\end{array}$ & $\begin{array}{l}\text { Diabetes-free life } \\
\text { expectancy (years) }\end{array}$ & $\begin{array}{l}\% \text { of remaining } \\
\text { life without diabetes }\end{array}$ & $\begin{array}{l}\text { Life } \\
\text { expectancy (years) }\end{array}$ & $\begin{array}{l}\text { Diabetes-free } \\
\text { life expectancy } \\
\text { (years) }\end{array}$ & $\begin{array}{l}\% \text { of remaining } \\
\text { life without } \\
\text { diabetes }\end{array}$ \\
\hline \multicolumn{7}{|c|}{ Underweight/normal weight (BMI $<25 \mathrm{~kg} / \mathrm{m}^{2}$ ) } \\
\hline Age 20 years & 52.8 & 44.7 & 84.7 & 54.5 & 43.4 & 79.6 \\
\hline Age 40 years & 34.4 & 28.8 & 83.5 & 35.7 & 27.6 & 77.2 \\
\hline Age 60 years & 17.6 & 15.6 & 88.8 & 18.1 & 15.4 & 84.9 \\
\hline \multicolumn{7}{|c|}{ Overweight (BMI $\geq 25 \mathrm{~kg} / \mathrm{m}^{2}$ to $<30 \mathrm{~kg} / \mathrm{m}^{2}$ ) } \\
\hline Age 20 years & 51.5 & 34.8 & 67.4 & 53.9 & 36.2 & 67.1 \\
\hline Age 40 years & 33.6 & 22.2 & 66.2 & 35.2 & 23.0 & 65.3 \\
\hline Age 60 years & 17.3 & 13.1 & 76.0 & 17.9 & 13.6 & 76.1 \\
\hline \multicolumn{7}{|c|}{ Obese (BMI $\left.\geq 30 \mathrm{~kg} / \mathrm{m}^{2}\right)$} \\
\hline Age 20 years & 49.3 & 22.6 & 45.7 & 52.4 & 27.1 & 51.8 \\
\hline Age 40 years & 32.3 & 15.4 & 47.7 & 34.2 & 17.8 & 51.9 \\
\hline Age 60 years & 17.3 & 11.1 & 64.1 & 17.6 & 11.6 & 65.9 \\
\hline \multicolumn{7}{|l|}{ Total population } \\
\hline Age 20 years & 52.6 & 39.9 & 75.9 & 54.4 & 38.9 & 71.6 \\
\hline Age 40 years & 34.3 & 25.5 & 74.2 & 35.6 & 24.4 & 68.4 \\
\hline Age 60 years & 17.7 & 15.1 & 85.3 & 18.2 & 14.7 & 80.7 \\
\hline
\end{tabular}


Table 3 Lifetime risk of developing diabetes by South Asian BMI cut points in Indian metropolitan cities

\begin{tabular}{lcl}
\hline BMI group & \multicolumn{2}{l}{ Lifetime risk } \\
\cline { 2 - 3 } & \multicolumn{1}{c}{ Men } & Women \\
\hline Underweight/normal weight $\left(\mathrm{BMI}<23 \mathrm{~kg} / \mathrm{m}^{2}\right)$ & \\
Age 20 years & $37.4(33.1,44.3)$ & $46.8(41.4,53.0)$ \\
Age 40 years & $32.0(27.5,39.2)$ & $42.2(36.0,48.8)$ \\
Age 60 years & $20.3(15.2,28.3)$ & $27.0(20.8,34.6)$ \\
Overweight $\left(\mathrm{BMI} \geq 23 \mathrm{~kg} / \mathrm{m}^{2}\right.$ to $\left.<27.5 \mathrm{~kg} / \mathrm{m}^{2}\right)$ & \\
Age 20 years & $63.6(55.6,71.9)$ & $67.6(56.9,75.2)$ \\
Age 40 years & $55.7(46.9,64.8)$ & $63.1(51.3,71.9)$ \\
Age 60 years & $37.8(25.5,49.4)$ & $44.2(31.1,56.8)$ \\
Obese $\left(\right.$ BMI $\left.\geq 27.5 \mathrm{~kg} / \mathrm{m}^{2}\right)$ & \\
Age 20 years & $83.3(73.0,91.1)$ & $80.3(69.5,88.3)$ \\
Age 40 years & $73.8(60.8,83.4)$ & $72.1(59.6,83.7)$ \\
Age 60 years & $53.5(31.5,71.8)$ & $49.5(29.3,72.6)$ \\
\hline
\end{tabular}

Lifetime risk is presented as \% $(95 \% \mathrm{CI})$

Table 7). Overall lifetime risk (95\% CI) at age 20 years among men and women, respectively, was $55.0(51.1,58.7) \%$ and $59.2(54.9,63.7) \%$ and decreased to $29.0(25.0,33.5) \%$ and $32.8(27.5,37.7) \%$ at age 60 years. Again, this masked considerable variation by BMI, whereby the lifetime risk $(95 \% \mathrm{CI})$ at age 20 years in men and women, respectively, was as follows: $40.0(36.4,43.3) \%$ and $40.6(35.9,45.2) \%$ among underweight/normal-weight individuals; $69.9(63.7,75.1) \%$ and $69.3(62.8,75.2) \%$ among overweight individuals; and 88.9 (82.2, 93.3)\% and 85.3 (77.3, 92.4)\% among obese individuals.

We also estimated lifetime risks of developing diabetes according to waist circumference. At age 20 years, the lifetime risk $(95 \% \mathrm{CI})$ was $71.0(64.4,80.9) \%$ for men with a waist circumference $\geq 90 \mathrm{~cm}$ and $45.2(40.9,48.8) \%$ for men with a waist circumference $<90 \mathrm{~cm}$ (ESM Table 8). Among women aged 20 years, the lifetime risk $(95 \%$ CI) was 75.5 (65.2, $84.2) \%$ for those with waist circumference $\geq 80 \mathrm{~cm}$ and 44.5 $(39.6,49.4) \%$ for those with waist circumference $<80 \mathrm{~cm}$.

Using the 2040 forecasted BMI group distribution in urban India, we estimated that the overall lifetime risk (95\% CI) of developing diabetes among individuals aged 20 years would increase to $64.0(60.0,66.8) \%$ and $77.1(71.0,81.7) \%$ for men and women, respectively (ESM Table 9).

\section{Discussion}

We found that in metropolitan India, the lifetime risk of developing diabetes among women and men without diabetes at age 20 years was $64.6 \%$ and $55.5 \%$, respectively. The lifetime risk was consistently higher among women compared with men and declined with age. Two in five underweight/ normal-weight 20-year-old men and over half of the underweight/normal-weight 20 -year-old women were projected to develop diabetes, and the remaining risk increased to over eight in ten among obese individuals aged 20 years. We also found that obese metropolitans can expect to spend the greatest percentage of their remaining life with diabetes (around 50\% from age 20 years).

These estimations relied on a number of assumptions. First, the model assumed that BMI-specific age-specific diabetes incidence will be constant throughout the lifetime of the cohort. This is a reasonable assumption given the lack of evidence as to how future BMI-specific diabetes incidence will develop. Second, we assumed that the transition to diabetes is permanent and that an individual cannot transition back to not having diabetes, an assumption we decided was reasonable given the relative rarity of spontaneous remission from diabetes. Third, we assumed that the RR of dying among those with diabetes relative to those without will remain constant into the future. The extent to which results changed through relaxation of this assumptions was negligible.

Our study has a number of strengths. Blood tests were used to identify diabetes and BMI was also objectively measured rather than using self-reports. Studies assessing the validity of self-reported diabetes have found considerable misclassification. For instance, one study found a sensitivity of selfreported diabetes in China was around 58.2\% in urban areas and $35.0 \%$ in rural areas [27]. Low sensitivity of self-reported diabetes has the potential to underestimate the lifetime risk estimates of previous studies [2], potentially explaining differences between ours and previous findings from different settings. We also used data sources that are designed to be geographically representative to measure mortality rates, BMI and diabetes. As data on national-level incidence of diabetes are not available, we obtained incidence rates from a large well-characterised, well-retained and followed up, representative cohort in urban areas of North and South India, making our results both geographically representative and generalisable to the wider metropolitan population. Finally, we performed extensive sensitivity analyses, reporting a range of uncertainty around our estimates, providing supplementary lifetime risk estimates using South Asianspecific BMI cut-offs, accommodating for potential overestimation of diabetes incidence when using $\mathrm{HbA}_{1 \mathrm{c}}$ by using solely FPG and diabetes treatment to classify diabetes cases, and examining the sensitivity of the estimates to initial diabetes prevalence by using diabetes prevalence estimated in the CARRS cohort.

Our study also has a number of limitations. First, assuming that age-specific rates will prevail over the projection period may have led us to both underestimate lifetime risk of diabetes within a BMI group (as the individual BMI distribution within 
a broad BMI group shifts to the right) and underestimate the overall lifetime risk for the total population (as the prevalence of excessive weight and obesity has increased in recent decades [21], and will likely increase into the future). One study in the USA identified increases in overall population lifetime risk of 20 and 13 percentage points in men and women, respectively between 1985 and 2011 [6]. The latter concern was addressed in sensitivity analysis using forecasted prevalence of excessive weight and obesity in urban India. Second, life expectancy at all ages in India is expected to continue to increase over the coming years [28]. Longer life expectancies may increase the lifetime risk of diabetes, making our results possible underestimates. Third, the socioeconomic distribution of excessive weight and obesity is likely to continue to change. A recent study has documented an increasing proportion of the overweight and obese population coming from lower socioeconomic backgrounds [29] among whom the RR of dying compared with people from higher socioeconomic backgrounds is likely to be higher. This may have led us to potentially overestimate the lifetime risk for the obese people. Our results should be interpreted with some caution, especially given India's considerable heterogeneity, somewhat limiting the generalisability of our findings to all of urban India. The results from this study relate to an average urban-dwelling individual in two highly urbanised areas; however, the extent of variation in lifetime risk and years of life lost to diabetes will depend on how much a particular individual differs from this average in regards their risk of diabetes [2, 30].

To our knowledge, this is the only study estimating the lifetime risk of diabetes in urban India. A comparison of our findings from those reported in HICs indicates an alarmingly high lifetime risk at every age in urban India. Recent data from the Netherlands indicates a $31.3 \%$ lifetime risk of diabetes among 45-year-olds; this contrasts with the reported $53.8 \%$ in urban Indian men and $55.4 \%$ in urban Indian women of the same age [4]. A study from the USA, using data from 2000-2011, reported a lifetime risk of diabetes of $40.2 \%$ among men and $39.6 \%$ among women aged 20 years. Our results are much closer to estimates of lifetime risk of diabetes among the black and Hispanic populations in the USA, groups considered at a higher risk of developing diabetes than the general population. A recent study found lifetime risks of developing diabetes in excess of $55.2 \%$ among black women and $51.5 \%$ in Hispanic women aged 20 years in the USA [6]. The higher lifetime risk among black and Hispanic women in the USA is driven by higher incidence when compared with white women. A study of diabetes incidence comparing urban Indian adults with black and white US residents reported consistently higher incidence in urban South Asians at all ages and BMI levels [11]. Overall, we posit that the considerably higher lifetime risk is driven by a relatively high predisposition to developing diabetes among Indians at both lower ages (up to a decade earlier) and lower BMIs when compared with white European populations [5].

On average, $70.1 \%$ of the remaining lifespan of the average woman and $74.0 \%$ of the remaining life of the average man without diabetes at the age of 20 years can be expected to be spent diabetes free; this proportion decreases considerably with increasing BMI. Attenuated results have been found in HICs; one study reported that Australians aged 25 years will spend $86 \%$ of their remaining years diabetes free [3], whereas a USA-based study found that women aged 18 years who were obese and severely obese could expect to spend around $80 \%$ and $65 \%$, respectively, of their remaining life diabetes free [2].

The remarkably high lifetime risk of developing diabetes and the low diabetes-free life expectancy in urban India, especially for individuals with high BMI, implies that interventions targeting the incidence of diabetes may be of paramount importance moving forward. The importance is reinforced by the early onset of diabetes among South Asians, implying a greater proportion of life spent with diabetes and greater exposure to diabetes-related complications. Potentially effective interventions include high and sustained sugar-sweetened beverage taxation [31] or diabetes prevention programmes involving a combination of culturally tailored lifestyle interventions with a course of medication [32]. The success of any intervention will also require improved detection of individuals with diabetes and either impaired glucose tolerance or impaired fasting glucose, given that an estimated $57 \%$ of diabetes cases are undiagnosed in India [1]. Although in India the advancement from either impaired glucose tolerance or impaired fasting glucose to diabetes has been found to be comparatively faster than in other populations [7, 33], any level of insulin resistance adds to a very sobering picture of dysglycaemia and associated complications in a country where urban obesogenic environments are on the increase and public health infrastructure is strained. Additional strain is also likely to be exerted on individual families as personal expenditure on diabetes care can be as high as $34 \%$ of household income for some low-income urban families [34].

Metropolitan Indians at every age and BMI have an alarmingly high probability of developing diabetes compared with results from HICs, necessitating a strong demand for proactive efforts to prevent diabetes in metropolitan cities, given the rapid increase in urban obesogenic environments across the country [35]. Prevention of diabetes, especially in younger metropolitan Indians, should be a high priority for India. Future research into rural lifetime risks of diabetes, using diabetes incidence rates from such settings, is encouraged to provide a more complete snapshot of the overall lifetime risk of diabetes at the national level. 
Supplementary Information The online version contains peer-reviewed but unedited supplementary material available at https://doi.org/10.1007/ s00125-020-05330-1.

Data availability The publicly available SRS data have been deposited in the Office of the Registrar General \& Census Commissioner repository (available at: http://censusindia.gov.in/vital_statistics/SRS_Based/SRS Based.html). Data from the CARRS and the ICMR-INDIAB study can be accessed through liaison with the study's principal investigators.

Funding This specific research was funded by the Economic and Social Research Council (https://esrc.ukri.org; grant no. ES/J500021/1 to SL). This funder had no role in study design, data collection and analysis, decision to publish or preparation of the manuscript. CARRS was funded in part by the National Heart, Lung, and Blood Institute (NHLBI), National Institutes of Health (NIH), Department of Health and Human Services, under Contract No. HHSN268200900026C, and the United Health Group, Minneapolis, MN, USA. KMVN, MKA and SAP were funded in part by the National Institute of Diabetes and Digestive and Kidney Diseases of the NIH under award no. P30DK111024. KMVN was funded in part for 'Worksite Lifestyle Program for Reducing Diabetes and Cardiovascular Risk in India' project funded by NHLBI, NIH, Department of Health and Human Services under award no. R01HL125442. SAP, KMVN, MKA, NT and DP were supported in part by the NHLBI of the NIH, award no. 5U01HL138635 under the Hypertension Outcomes for T4 Research within Lower Middle-Income Countries (Hy-TREC) program. DK has been supported by Fogarty International Center for PH Leader Course, NIH under grant no. D43TW009135.

Authors' relationships and activities The authors declare that there are no relationships or activities that might bias, or be perceived to bias, their work.

Contribution statement SL, RJ, SK, LC and KMVN all helped develop the concept and design the study. The acquisition of data was done by DK, RMA, MKA, SAP, DP, MK, VM, NT and KMVN. Statistical analysis of the data was performed by SL. All authors made substantial contributions to the interpretation of results. SL and KMVN drafted the manuscript and all authors contributed to the critical revision of the manuscript for important intellectual content. SL had full access to all of the data in the study and takes responsibility for the integrity of the data and the accuracy of the data analysis. All authors approved the final manuscript for publication.

Open Access This article is licensed under a Creative Commons Attribution 4.0 International License, which permits use, sharing, adaptation, distribution and reproduction in any medium or format, as long as you give appropriate credit to the original author(s) and the source, provide a link to the Creative Commons licence, and indicate if changes were made. The images or other third party material in this article are included in the article's Creative Commons licence, unless indicated otherwise in a credit line to the material. If material is not included in the article's Creative Commons licence and your intended use is not permitted by statutory regulation or exceeds the permitted use, you will need to obtain permission directly from the copyright holder. To view a copy of this licence, visit http://creativecommons.org/licenses/by/4.0/.

\section{References}

1. International Diabetes Federation (ed) (2019) IDF Diabetes Atlas, 9th edn. International Diabetes Federation, Brussels, Belgium
2. Narayan KMV, Boyle JP, Thompson TJ, Gregg EW, Williamson DFW (2007) Effect of BMI on lifetime risk for diabetes. Diabetes Care 30:1562-1566. https://doi.org/10.2337/dc06-2544

3. Magliano DJ, Shaw JE, Shortreed SM, Nusselder WJ, Liew D, Barr ELM et al (2008) Lifetime risk and projected population prevalence of diabetes. Diabetologia 51:2179-2186. https://doi.org/10.1007/ s00125-008-1150-5

4. Ligthart S, van Herpt TTW, Leening MJG, Kavousi M, Hofman A, Stricker BHC et al (2016) Lifetime risk of developing impaired glucose metabolism and eventual progression from prediabetes to type 2 diabetes: a prospective cohort study. Lancet Diabetes Endocrinol 4:44-51. https://doi.org/10.1016/S2213-8587(15) 00362-9

5. Narayan KMV, Kanaya AM (2020) Why are South Asians prone to type 2 diabetes? A hypothesis based on underexplored pathways. Diabetologia 63(6):1103-1109. https://doi.org/10.1007/s00125020-05132-5

6. Gregg EW, Zhuo X, Cheng YJ, Albright AL, Narayan KMV, Thompson TJ (2014) Trends in lifetime risk and years of life lost due to diabetes in the USA, 1985-2011: a modelling study. Lancet Diabetes Endocrinol 2:867-874. https://doi.org/10.1016/S22138587(14)70161-5

7. Tandon N, Anjana RM, Mohan V, Kaur T, Afshin A, Ong K et al (2018) The increasing burden of diabetes and variations among the states of India: the Global Burden of Disease Study 1990-2016. Lancet Glob Health 6:e1352-e1362

8. Sikarwar A, Chattopadhyay A (2020) Analyzing population and land use change: selected case studies of Indian metropolitan cities. Springer Nature, Singapore

9. Office of the Registrar General \& Census Commissioner, India (2011) List of towns and their population. Available from https:// censusindia.gov.in/towns/town.aspx. Accessed 11 Sept 2020

10. Narayan VKM, Kondal D, Daya NR et al (2019) Incidence of diabetes in young adult South Asians compared with Pima Indians. Diabetes 68(Suppl 1):1597. https://doi.org/10.2337/db191597-P

11. Narayan VKM, Kondal D, Daya NR et al (2019) 1598-P: Incidence of diabetes in South Asian adults in urban India/Pakistan compared with blacks and whites in U.S. Diabetes 68(Suppl 1):1598. https:// doi.org/10.2337/db19-1598-P

12. WHO (2016) Obesity and overweight. Available from http://www. who.int/mediacentre/factsheets/fs311/en/. Accessed 13 July 2017

13. Office of the Registrar General \& Census Commissioner, India (2019) SRS based abridged life tables 2013-17. Available from https://censusindia.gov.in/vital statistics/Appendix SRS Based Life Table.html. Accessed 13 June 2020

14. Preston SH, Heuveline P, Guillot M (2000) Demography: measuring and modeling population processes. Wiley-Blackwell, Hoboken, $\mathrm{p} 6$

15. Pascariu M (2018) MortalityLaws: parametric mortality models, life tables and HMD. R package version, 1(0). Available from https://cran.r-project.org/web/packages/MortalityLaws/index.html

16. Nwaneri C, Cooper H, Bowen-Jones D (2013) Mortality in type 2 diabetes mellitus: magnitude of the evidence from a systematic review and meta-analysis. Br J Diabetes Vasc Dis 13:192-207. https://doi.org/10.1177/1474651413495703

17. Pednekar MS, Hakama M, Hebert JR, Gupta PC (2008) Association of body mass index with all-cause and cause-specific mortality: findings from a prospective cohort study in Mumbai (Bombay), India. Int J Epidemiol 37:524-535. https://doi.org/10. 1093/ije/dyn001

18. Anjana RM, Deepa M, Pradeepa R, Mahanta J, Narain K, Das HK et al (2017) Prevalence of diabetes and prediabetes in 15 states of India: results from the ICMR - INDIAB population-based crosssectional study. Lancet Diabetes Endocrinol 5:585-596. https://doi. org/10.1016/S2213-8587(17)30174-2 
19. Priya M, Mohan Anjana R, Pradeepa R, Jayashri R, Deepa M, Bhansali A et al (2011) Comparison of capillary whole blood versus venous plasma glucose estimations in screening for diabetes mellitus in epidemiological studies in developing countries. Diabetes Technol Ther 13:586-591. https://doi.org/10.1089/dia. 2010.0218

20. Luhar S, Timæus IM, Jones R, Cunningham S, Patel SA, Kinra S et al (2020) Forecasting the prevalence of overweight and obesity in India to 2040. PLoS One 15:e229438. https://doi.org/10.1371/ journal.pone. 0229438

21. International Institute for Population Sciences (2017) National Family Health Survey (NFHS-4) 2015-16 India. International Institute for Population Sciences (IIPS) and ICF Available from http://rchiips.org/nfhs/NFHS-4Reports/India.pdf. Accessed 1 Feb 2018

22. Arokiasamy P, Parasuraman S, Sekher TV, Lhungdim H (2013) Study on global AGEing and adult health (SAGE), Wave 1. World Health Organization. Available from https://apps.who.int/ healthinfo/systems/surveydata/index.php/catalog/sage. Accessed Jan 2018

23. Roth G, Caswell H (2018) Occupancy time in sets of states for demographic models. Theor Popul Biol 120:62-77. https://doi. org/10.1016/j.tpb.2017.12.007

24. Nishida C, Barba C, Cavalli-Sforza T, Cutter J, Deurenberg P, Darnton-Hill I et al (2004) Appropriate body-mass index for Asian populations and its implications for policy and intervention strategies. Lancet 363:157

25. Deepa M, Grace M, Binukumar B, Pradeepa R, Roopa S, Khan HM et al (2015) High burden of prediabetes and diabetes in three large cities in South Asia: the Center for cArdio-metabolic Risk Reduction in South Asia (CARRS) Study. Diabetes Res Clin Pract 110:172-182. https://doi.org/10.1016/j.diabres.2015.09.005

26. Gujral UP, Prabhakaran D, Pradeepa R, Kandula NR, Kondal D, Deepa $M$ et al (2019) Isolated HbA1c identifies a different subgroup of individuals with type 2 diabetes compared to fasting or post-challenge glucose in Asian Indians: the CARRS and MASALA studies. Diabetes Res Clin Pract 153:93-102. https:// doi.org/10.1016/j.diabres.2019.05.026

27. Yuan X, Liu T, Wu L, Zou ZY, Li C (2015) Validity of selfreported diabetes among middle-aged and older Chinese adults: the China Health and Retirement Longitudinal Study. BMJ Open 5:1-7

28. Yadav A, Yadav S, Kesarwani R (2012) Decelerating mortality rates in older ages and its prospects through Lee-Carter approach. PLoS One 7:e50941. https://doi.org/10.1371/journal.pone.0050941

29. Luhar S, Mallinson PAC, Clarke L, Kinra S (2018) Trends in the socioeconomic patterning of overweight/obesity in India: a repeated cross-sectional study using nationally representative data. BMJ Open 8:e023935. https://doi.org/10.1136/bmjopen-2018-023935

30. Narayan KMV, Boyle JP, Thompson TJ, Sorensen SW, Williamson DF (2003) Lifetime risk for diabetes mellitus in the United States. J Am Med Assoc 290:1884-1890. https://doi.org/ 10.1001/jama.290.14.1884

31. Basu S, Vellakkal S, Agrawal S, Stuckler D, Popkin B, Ebrahim S (2014) Averting obesity and type 2 diabetes in India through sugarsweetened beverage taxation: an economic-epidemiologic modeling study. PLoS Med 11:e1001582. https://doi.org/10.1371/journal. pmed.1001582

32. Weber MB, Ranjani H, Staimez LR, Anjana RM, Ali MK, Narayan KMV et al (2016) The stepwise approach to diabetes prevention: results from the D-CLIP randomized controlled trial. Diabetes Care 39:1760-1767. https://doi.org/10.2337/dc16-1241

33. Anjana RM, Rani CSS, Deepa M, Pradeepa R, Sudha V, Nair HD et al (2015) Incidence of diabetes and prediabetes and predictors of progression among Asian Indians: 10-year follow-up of the Chennai urban rural epidemiology study (CURES). Diabetes Care 38:1441-1448. https://doi.org/10.2337/dc14-2814

34. Ramachandran A, Ramachandran S, Snehalatha C, Augustine C, Murugesan N, Viswanathan V et al (2007) Increasing expenditure on health care incurred by diabetic subjects in a developing country: a study from India. Diabetes Care 30:252-256. https://doi.org/10. 2337/dc06-0144

35. UN-DESA (2018) World urbanization prospects: the 2018 revision. Department of Economic and Social Affairs. Available from https:// population.un.org/wup/. Accessed 5 Sept 2019

Publisher's note Springer Nature remains neutral with regard to jurisdictional claims in published maps and institutional affiliations. 